20

\title{
Электрические и вязкоупругие параметры эритроцитов в моделях для диагностики аденоматозных полипов и стадий колоректального рака при оптической детекции клеток в неоднородном переменном электрическом поле
}

(C) М.В. Кручинина ${ }^{1,4}$, А.А. Громов ${ }^{1}$, Л.В. Щербакова ${ }^{1}$, Э.В. Кручинина ${ }^{4}$, В.М. Генералов ${ }^{2}$, К.В. Генералов ${ }^{2}$, В.Н. Кручинин ${ }^{3}$, С.В. Рыхлицкий ${ }^{3}$, И.Н. Яковина ${ }^{5}$, М.В. Яковлев ${ }^{5}$, О.В. Минин ${ }^{6}$, И.В. Минин

${ }^{1}$ НИИ терапии и профилактической медицины - фрилиал Федерального государственного бюджетного научного учреждения „Федеральный исследовательский центр Институт цитологии и генетики Сибирского отделения

Российской академии наук",

630089 Новосибирск, Россия

${ }^{2}$ Государственный научный центр вирусологии и биотехнологии „Вектор“

Федеральной службы по надзору в сфере защиты прав потребителей и благополучия человека,

Кольцово, Новосибирская обл., Россия

${ }^{3}$ Институт фризики полупроводников им. А.В. Ржанова Сибирского отделения РАН,

630090 Новосибирск, Россия

${ }^{4}$ Новосибирский государственный медицинский университет,

630091 Новосибирск, Россия

${ }^{5}$ Новосибирский государственный технический университет,

630073 Новосибирск, Россия

${ }^{6}$ Сибирский государственный университет геосистем и технологий,

630108 Новосибирск, Россия

e-mail: kruchmargo@yandex.ru

Поступила в редакцию 22.12.2020 г.

В окончательной редакции 11.01.2021 г.

Принята к публикации 26.02.2021 г.

С помощью метода диэлектрофореза в неоднородном переменном электрическом поле при использовании оптической системы детекции клеток проведено исследование электрических и вязкоупругих параметров эритроцитов в частотном диапазоне от $5 \cdot 10^{4}$ до $1 \cdot 10^{6} \mathrm{MHz}$ у 129 больных с колоректальным раком (КРР) различных стадий развития заболевания, 25 человек с аденоматозными полипами и 35 лиц группы сравнения. Показано, что величины физических характеристик эритроцитов значимо различаются как при сопоставлении групп контроля и пациентов с аденоматозными полипами и больных с ранними стадиями КРР, так и при сравнении пациентов с различными стадиями онкологического процесса между собой. Построение $S H A P$-графиков на основе электрических и вязкоупругих параметров эритроцитов позволило достичь $100 \%$ диагностической точности при различении пациентов с аденоматозными полипами, ранними стадиями КРР от здоровых лиц, 98.7\% точности - при дифференцировании пациентов с полипами от больных с ранними стадиями КРР, 91.9\% точности - при различении ранних и поздних стадий КРР. Полученные результаты демонстрируют высокий потенциал предложенного метода для скрининга и диагностики КРР.

Ключевые слова: диэлектрофорез, эритроциты, электрические и вязкоупругие параметры, диагностика, колоректальный рак, аденоматозные полипы, SHAP-графики.

DOI: $10.21883 /$ OS.2021.06.50978.2-21

\section{Введение}

Во всем мире колоректальный рак (КРР) является третьим по распространенности типом онкологических заболеваний [1]. Ранняя диагностика КРР является ключом к выживанию пациентов [2,3]. В 90\% случаев развитию спорадического КРР предшествуют аденоматозные полипы, развившиеся в преклонном возрасте, которые являются предикторами злокачественной трансформации $[1]$, т.е. предраком. Поэтому выявление полипов и их удаление - это возможность предотвращения развития КРР. С другой стороны, выявление признаков прогрессирования заболевания при уже диагностированном раке в максимальные ранние сроки позволяет произвести резекцию отдельных метастатических образований, что значительно улучшает прогноз для пациента [4]. Широко используемые методы скрининга данного заболевания - исследование кала на скрытую кровь и колоноскопия - при наличии очевидных преимуществ (высокие чувствительность и специфичность в случае размера образования более $1 \mathrm{~cm}$ и факта истечения крови в просвет кишки) не лишены недостатков (не все опухоли и полипы кровоточат, истечение крови происходит фрагментарно, может отсутствовать в момент 
исследования). Инвазивность, высокая стоимость, риск осложнений, необходимость подготовки пациента ограничивают возможности применения колоноскопии [5]. Методы диагностики КРР предполагают использование комплекса инструментальных (рентгеноскопия - ирригоскопия, колонография, ультразвуковое исследование, компьютерная томография, магнитно-резонансная томография, позитронно-эмиссионная томография, эндоскопические методы - гибкая сигмоидоскопия, колоноскопия), молекулярно-генетических, биохимических методов, которые являются дорогостоящими, требуют специального оборудования, обученного персонала, некоторые сопряжены с лучевой нагрузкой, наличием осложнений для пациента [6]. Поэтому продолжается поиск подходов для раннего выявления КРР и выявления его прогрессирования с помощью методов, приемлемых и доступных пациенту, малоинвазивных, с возможностью исследования в динамике наблюдения, которые позволили бы сузить и ускорить диагностический процесс.

В клинической практике широко используется перечень параметров клеток красной крови - скорость оседания эритроцитов (отражает степень воспаления, иммунного ответа), средний корпускулярный объем эритроцитов (диагностика жировой болезни печени алкогольного и неалкогольного генеза, злоупотребления алкоголем), гликозилированный гемоглобин (отражает уровень компенсации сахарного диабета), омега-3индекс эритроцитов (независимый фактор риска внезапной коронарной смерти), средняя концентрация гемоглобина в эритроците ассоциирована с клиническими характеристиками и осложнениями острого инфаркта миокарда, показатель распределения эритроцитов по объему связан с уровнем смертности в общей популяции, среди пациентов с ишемической болезнью сердца и сердечной недостаточностью, степень сатурации крови, отражающая степень насыщения гемоглобина кислородом, является объективным критерием степени дыхательной недостаточности при патологии дыхательной системы [7]. С точки зрения имеющегося обширного клинического опыта использование электрических и вязкоупругих параметров эритроцитов в диагностических целях следует считать вполне уместным.

Диэлектрофорез (ДЭФ) клеток красной крови в неоднородном переменном электромагнитном поле (НПЭП) представляется перспективным методом с этой точки зрения. Он позволяет определить более 20 физических и физико-химических параметров клеток, в том числе ключевые при описании моделей развития и прогрессирования патологического процесса [8]. Проведенные ранее пилотные исследования у пациентов с КРР различных стадий, а также в динамике проведенной терапии показали наличие значимых различий электрических и вязкоупругих показателей эритроцитов, ассоциированных со стадией заболевания [9]. Поскольку клетки красной крови являются чувствительными к развитию патологических процессов, а целый ряд вязкоупругих и электрических параметров позволяет выявить эти начальные изменения, мы предположили, что пациенты с аденоматозными полипами (предраком) будут иметь особенности эритроцитов, доступные для выявления методом диэлектрофореза. В представленных ранее работах продемонстрированы разработанные рискометры для различения пациентов с КРР от здоровых лиц между стадиями заболевания с использованием методов системного и графического анализа. Диагностические модели формировались с учетом разных шкал, при этом оценивались выраженные кластеры для исследуемых диагностических групп по ряду параметров. При наличии определенных достоинств данного подхода (ограниченное количество анализируемых параметров при решении перечня диагностических задач, доступность статистической обработки) [8] выявились и недостатки. В частности, недостаточная диагностическая точность при дифференцировании больных от здоровых и между ранними и поздними стадиями КРР (специфичность 0.640). И что особенно важно для клинической практики, невозможность дифференцирования предрака, раннего рака и различения между ними.

Арсенал методов прикладного анализа данных, используемых для анализа малых выборок большой размерности, активно пополняется. Ранее разработанные на основе вероятностно-статистического и логикоматематического подходов модели не позволили получить результаты максимальной точности и информационной полноты [8]. Эта задача была решена с применением методов машинного обучения. Одним из таких средств решения поставленной задачи, учитывающих специфику данных, являются методы, которые используют для создания диагностических моделей деревья решений. Модель, полученная на основе деревьев решений, позволит получить вероятность отнесения пациента к выделенным диагностическим группам. При этом важно при ее формировании не допустить ошибки первого рода и причислить больного пациента к здоровым или наоборот [10]. Одно бинарное дерево является довольно нестабильным алгоритмом принятия решений из-за возможных шумов, неоднородности и смещений в обучающих данных. Для уменьшения ошибки классификации были использованы ансамбли деревьев [11]. Ансамбли представляют собой совокупность деревьев решений, которые дают набор предсказателей, и путем усреднения предсказаний ошибка классификации уменьшается.

Исходя из специфики задачи и критичности ошибки первого рода для оценки качества полученных результатов были выбраны такие метрики, как точность, специфичности, чувствительность и ROC (Receiver Operating Characteristic - „рабочая характеристика приемника“, оценка качества бинарной классификации; количественную информацию дает $A U C$ - Area Under ROC Curve, площадь под ROC-кривой). Для решения поставленной задачи были использованы различные библиотеки высокоуровневого языка программирования Python (pandas, numpy, scikit-learn, catboost, xgboost, lightgbm, plotly 
идр.). В ходе работы было разработано 4 алгоритма (модели).

Для анализа полученного результата и выявления наиболее информативных признаков, с чем также довольно хорошо справляются деревья решений, был использован $S H A P$-график, который отражает важность используемых в модели признаков или степень влияния отдельных предикторов на целевую переменную (индикатор диагностируемого класса) [12]. Самым большим отличием этого графика от других вариантов отображения результатов является то, что он показывает положительные и отрицательные отношения предикторов (показателей) с целевой переменной. График интерпретируется следующим образом.

- Важность переменных: ранжируются сверху вниз в порядке убывания важности вклада в целевую переменную.

- Степень вклада в целевую переменную: значения слева от центральной вертикальной линии (0) - это negative класс (-1), справа - positive (1).

- Значения признаков: чем краснее точки, тем большее значение имеет признак в этой точке.

- Распределение значений признаков: толщина линии прямо пропорциональна количеству точек наблюдения (чем толще линия на графике, тем больше таких точек наблюдения).

Цель работы - изучить возможности использования электрических и вязкоупругих параметров эритроцитов в качестве компонентов математических моделей для диагностики аденоматозных полипов и стадий КРР.

\section{Методы исследований}

Обследованы 129 пациентов с КРР (средний возраст $62.8 \pm 9.4$ year (68 мужчин, 61 женщина) - из них 65 с ранними стадиями КРР (1-2 стадии), 64 с поздними стадиями рака толстой кишки (3-4 стадии), 25 человек с аденоматозными полипами (62.2 \pm 9.4 year, 12 мужчин, 13 женщин) и 35 человек группы сравнения (58.6 \pm 6.9 year, 19 мужчин, 16 женщин). Больные поступали в ГБУЗ НСО „Новосибирский областной онкологический диспансер“ с гистологически подтвержденным КРР (аденокарцинома). Всем пациентам опухоль толстой кишки была диагностирована впервые. Определение стадии опухоли толстой кишки уточнено после операции с исследованием патологического образца и с учетом наличия метастазирования в регионарные лимфатические узлы или обнаружения отдаленных метастазов в соответствии с классификацией по TNM. Локализация опухолей была различна. У 25 пациентов опухоль выявлена в проксимальной части толстой кишки, включая слепую кишку (13), восходящий (5) и поперечноободочный (7) отделы толстой кишки; в 98 случаях очаг локализовался в дистальной ободочной кишке: в нисходящей (4) и сигмовидной (36); у значительного числа пациентов (58) опухоль обнаружена в прямой кишке. 6 пациентов имели первично-множественную локализацию опухолей в толстой кишке. По наличию метастазов в регионарных лимфатических узлах установлено, что у 65 (50\%) пациентов поражения регионарных лимфоузлов не выявлено (N0), у 26 человек (20.2\%) выявлены метастазы в 1-3 (включительно) регионарных лимфатических узлах $(N 1)$, метастазы в более чем трех регионарных лимфатических узлах (N2) определены у оставшихся пациентов (29.8\%).

Наличие отдаленных метастазов $(M)$ установлено у 22 пациентов: в большинстве случаев (14 пациентов) выявлены отдаленные метастазы в печень $(M 1 a)$, у 6 больных - множественные метастазы в печень и легкие (в двух случаях) метастазы в печень и брюшину (M1b).

Исследование выполнено с одобрения Комитета Биомедицинской Этики Федерального государственного бюджетного научного учреждения „Научноисследовательский институт терапии и профилактической медицины“ (29.11.2016, протокол № 123). Все пациенты подписали информированное согласие на участие в исследовании.

Всем пациентам и лицам группы сравнения, кроме общеклинических и инструментальных методов исследования, было проведено исследование электрических и вязкоупругих параметров эритроцитов методом диэлектрофореза с помощью оптической системы детекции клеток (автоматизированной специализированной установки, рис. 1) в частотном диапазоне от $5 \cdot 10^{4}$ до $1 \cdot 10^{6} \mathrm{MHz}$. Проведение измерений на установке основывается на следующем: дипольный момент $d_{\text {cel }}$ и средняя сила электрического поля $\left\langle\mathbf{F}_{\text {cel }}^{*}\right\rangle$, действующая на клетку, изменяются как за счет величины поляризуемости $a^{*}$, так и градиента квадрата напряженности электрического поля $\nabla E_{\mathrm{av}}^{2}$. Градиент напряженности электрического поля $\nabla E_{\mathrm{av}}$ формируется геометрическими размерами электродов и величиной напряжения на них [13], при этом один из линейных размеров электродов целесообразно выбирать примерно на порядок меньше диаметра анализируемой клетки. Характерным размером электрода является его толщина, при которой достигаются существенные градиенты электрического поля. Установлено, что для эритроцитов человека толщину электрода следует выбирают равной $\sim 0.2 \cdot 10^{-6} \mathrm{~m}[14]$. При этом покровное стекло может быть модифицировано путем нанесения на ее заднюю поверхность одной или более мезо-размерных диэлектрических частиц, формирующих фотонные наноструи для увеличения оптического разрешения [15]. Более детально особенности конструкции и проведение измерений на установке описаны в монографии [14]. Подготовка взвесей эритроцитов для проведения исследования описана в работе [16]. В ходе измерений оценивали средний радиус эритроцитов (в том числе на различных частотах исследуемого диапазона), доли дискоцитарных, сфероцитарных, деформированных форм эритроцитов, характер поверхности клеток, индексы агрегации и деструкции 

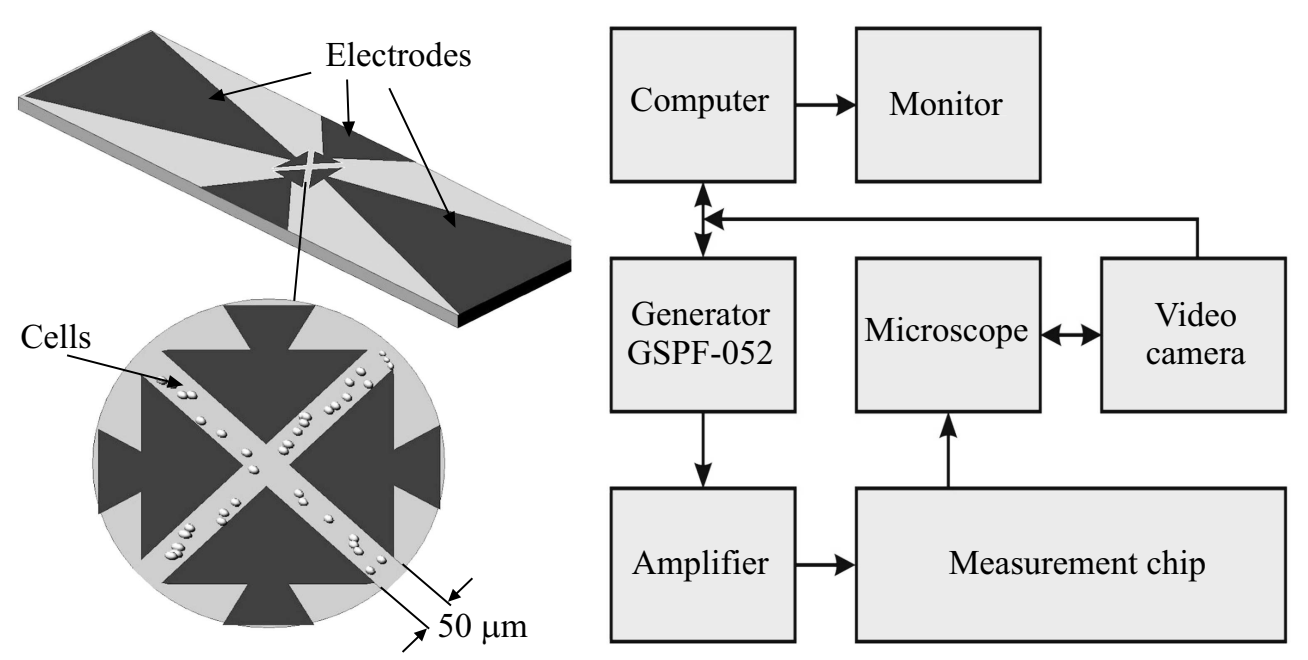

Рис. 1. Схематический вид измерительной ячейки (слева) и функциональная схема электрооптической детекции клеток (справа).

на различных частотах НПЭП, электропроводность, емкость мембран клеток, скорость движения эритроцитов к электродам, положение равновесной частоты, амплитуду деформации на частоте $1 \cdot 10^{6} \mathrm{~Hz}$, степень деформации клеток на частоте $5 \cdot 10^{5} \mathrm{~Hz}$, обобщенные показатели вязкости и жесткости, величины индуцированного дипольного момента, поляризуемость клеток на частоте $1 \cdot 10^{6} \mathrm{~Hz}$, относительную поляризуемость (отношение поляризуемости на частоте $1 \cdot 10^{6} \mathrm{~Hz}$ к величине показателя на частоте $1 \cdot 10^{5} \mathrm{~Hz}$ ) [17].

Статистическая обработка данных выполнена с помощью программы SPSS, ver.17. Достоверность различия показателей оценивали с использованием непараметрических критериев (U-критерий Манна-Уитни, Колмогорова-Смирнова). Во всех процедурах статистического анализа критический уровень значимости нулевой гипотезы $(p)$ принимался равным 0.05 .

Для построения диагностических моделей были построены графики SHAP в исследуемых парах групп пациентов: „группа сравнения - группа пациентов с полипами“, „группа сравнения - пациенты с ранними стадиями КРР“, „группа пациентов с полипами - группа с ранними стадиями КРР“, „группа с ранними стадиями КРР - группа с поздними стадиями КРР““.

Диагностическая точность полученных моделей оценивалась с помощью ROC-анализа.

\section{Результаты и обсуждение}

Особенности изменения электрических и вязкоупругих параметров клеток красной крови в НПЭП у лиц группы контроля и пациентов с полипами и КРР на всех частотах диапазона показаны в табл. 1 .

У пациентов с полипами и КРР выявлено достоверное снижение дискоцитарных форм эритроцитов на фоне значимого возрастания сфероцитов, иных форм эритроцитов с бугристой, шиповидной поверхностью по сравнению со здоровыми лицами $(p=0.023-0.0001)$. Пациенты с полипами отличались от больных с ранними стадиями КРР только по доле дискоцитов $(p=0.003)$.

Средний радиус клеток оказался достоверно ниже такового в контроле как у пациентов с полипами $(p=0.015)$, так и у больных с КРР $(p<0.0001)$, причём в поздние стадии этот показатель имел минимальные значения $(3.09 \pm 0.25 \mu \mathrm{m}$ в поздних стадиях против $3.22 \pm 0.24 \mu \mathrm{m}$ в ранних, $p=0.003)$. Уже в начальные стадии КРР этот параметр оказался ниже, чем в случаях аденоматозных полипов $(p<0.0001)$. Следует заметить, что в таблице приведены величины среднего радиуса эритроцитов (при рассмотрении всех частот НПЭП) с целью демонстрации обшей тенденции к изменению этого показателя в исследуемых группах. При построении диагностических моделей учитывался радиус клеток на различных частотах, поскольку это оказалось значимо для различения в попарно сравниваемых группах.

Амплитуда деформации эритроцитов на высоких частотах $\left(1 \cdot 10^{6}, 5 \cdot 10^{5} \mathrm{~Hz}\right)$ оказалась достоверно ниже у больных с полипами и больных с КРР, чем таковая у здоровых лиц $(p<0.0001)$. Однако если на частоте $1 \cdot 10^{6} \mathrm{~Hz}$ различия между пациентами с КРР (общая группа) и больными с полипами были достоверны $(p=0.006)$, то на $5 \cdot 10^{5} \mathrm{~Hz}$ степень деформации клеток у больных с КРР демонстрировала лишь тенденцию к снижению по сравнению с больными с полипами $(p=0.071)$. Стоит заметить, что ранние стадии КРР по данному параметру достоверно различались не только от здоровых лиц $(p<0.0001-0.003)$, но и от лиц с полипами (по степени деформации на частоте $5 \cdot 10^{5} \mathrm{~Hz}$, $p=0.037)$.

Обобщённый показатель жёсткости был достоверно выше у больных КРР, чем в группах здоровых лиц и пациентов с полипами $(p<0.0001)$. Вместе с тем при наличии аденоматозных полипов обобщённая жёсткость возрастала по сравнению с группой контроля 
Таблица 1. Электрические и вязкоупругие параметры эритроцитов больных с КРР, аденоматозными полипами и лиц группы сравнения $(M+S D)$

\begin{tabular}{|c|c|c|c|c|c|}
\hline \multirow[t]{2}{*}{ Показатель } & $\begin{array}{c}\text { Группа } \\
\text { сравнения } \\
(n=35)\end{array}$ & $\begin{array}{c}\text { Группа } \\
\text { пациентов } \\
\text { с полипами } \\
(n=25) \\
\end{array}$ & $\begin{array}{c}\text { Группа } \\
\text { с ранними } \\
\text { стадиями КРР } \\
(n=65) \\
\end{array}$ & $\begin{array}{c}\text { Группа } \\
\text { с поздними } \\
\text { стадиями КРР } \\
(n=64) \\
\end{array}$ & $p$ \\
\hline & $(1)$ & (2) & (3) & (4) & \\
\hline Средний радиус клеток, $\mu \mathrm{m}$ & $\begin{array}{c}3.56 \pm 0.98 \\
3.56 \\
(3.48 ; 3.62)\end{array}$ & $\begin{array}{c}3.50 \pm 0.04 \\
3.51 \\
(3.47 ; 3.53)\end{array}$ & $\begin{array}{c}3.22 \pm 0.24 \\
3.2 \\
(3.07 ; 3.37)\end{array}$ & $\begin{array}{c}3.09 \pm 0.25 \\
3.04 \\
(2.87 ; 3.27)\end{array}$ & $\begin{array}{l}p 1-p 2=0.015 \\
p 1-p 3<0.0001 \\
p 1-p 4<0.0001 \\
p 2-p 4<0.0001 \\
p 3-p 4=0.0001\end{array}$ \\
\hline Доля дискоцитов, \% & $\begin{array}{c}75.0 \pm 8.57 \\
74 \\
(70 ; 83)\end{array}$ & $\begin{array}{c}60.59 \pm 5.73 \\
62 \\
(56 ; 66)\end{array}$ & $\begin{array}{c}65.12 \pm 17.11 \\
70 \\
(61 ; 77)\end{array}$ & $\begin{array}{c}45.54 \pm 21.3 \\
42 \\
(24 ; 64)\end{array}$ & $\begin{array}{c}p 1-p 2=0.014 \\
p 1-p 3<0.071 \\
p 1-p 4<0.0001 \\
p 2-p 3=0.003 \\
p 2-p 4=0.023 \\
p 3-p 4<0.0001\end{array}$ \\
\hline Доля сфероцитов, \% & $\begin{array}{c}19.49 \pm 7.01 \\
19 \\
(13 ; 24)\end{array}$ & $\begin{array}{c}31.82 \pm 6.34 \\
32 \\
(26 ; 35.5)\end{array}$ & $\begin{array}{c}31.69 \pm 17.97 \\
26 \\
(20.5 ; 34.5)\end{array}$ & $\begin{array}{c}50.94 \pm 22.1 \\
50 \\
(34 ; 72)\end{array}$ & $\begin{array}{c}p 1-p 2=0.036 \\
p 1-p 3=0.012 \\
p 1-p 4<0.0001 \\
p 1-p 4<0.0001 \\
p 2-p 4<0.001 \\
p 3-p 4<0.0001\end{array}$ \\
\hline $\begin{array}{c}\text { Доля деформированных } \\
\text { клеток, \% }\end{array}$ & $\begin{array}{c}20.23 \pm 8.09 \\
18 \\
(13 ; 26)\end{array}$ & $\begin{array}{c}44.65 \pm 14.24 \\
40 \\
(34 ; 57.5)\end{array}$ & $\begin{array}{c}47.97 \pm 19.17 \\
42 \\
(33 ; 61.5)\end{array}$ & $\begin{array}{c}64.03 \pm 19.1 \\
67 \\
(51 ; 80)\end{array}$ & $\begin{array}{l}p 1-p 2<0.0001 \\
p 1-p 3<0.0001 \\
p 1-p 4<0.0001 \\
p 2-p 4<0.0001 \\
p 3-p 4<0.0001\end{array}$ \\
\hline $\begin{array}{c}\text { Амплитуда деформации } \\
\text { на } 1 \cdot 10^{6} \mathrm{~Hz}, 10^{-6} \mathrm{~m}\end{array}$ & $\begin{array}{c}8.26 \pm 0.68 \\
8.19 \\
(7.64 ; 8.88)\end{array}$ & $\begin{array}{c}6.65 \pm 0.38 \\
6.67 \\
(6.37 ; 6.92)\end{array}$ & $\begin{array}{c}6.71 \pm 0.72 \\
6.62 \\
(6.27 ; 7.21)\end{array}$ & $\begin{array}{l}5.79 \pm 0.55 \\
5.80 \\
(5.32 ; 6.24)\end{array}$ & $\begin{array}{l}p 1-p 2<0.0001 \\
p 1-p 3<0.0001 \\
p 1-p 4<0.0001 \\
p 2-p 4<0.0001 \\
p 3-p 4<0.0001\end{array}$ \\
\hline $\begin{array}{c}\text { Степень изменения } \\
\text { амплитуды деформации } \\
\text { на } 5 \cdot 10^{5} \mathrm{~Hz}, \%\end{array}$ & $\begin{array}{c}75.17 \pm 7.63 \\
74 \\
(68 ; 83)\end{array}$ & $\begin{array}{c}57.05 \pm 6.17 \\
58 \\
(52 ; 62)\end{array}$ & $\begin{array}{c}60.14 \pm 12.9 \\
64 \\
(53 ; 69)\end{array}$ & $\begin{array}{c}36.56 \pm 12.32 \\
36 \\
(26 ; 44)\end{array}$ & $\begin{array}{c}p 1-p 2<0.0001 \\
p 1-p 3=0.003 \\
p 1-p 4<0.0001 \\
p 2-p 3=0.037 \\
p 2-p 4<0.0001 \\
p 3-p 4<0.0001\end{array}$ \\
\hline $\begin{array}{c}\text { Обобщенный показатель } \\
\text { жесткости } \times 10^{-6}, \mathrm{~N} / \mathrm{m}\end{array}$ & $\begin{array}{c}6.56 \pm 0.91 \\
6.58 \\
(5.87 ; 7.12)\end{array}$ & $\begin{array}{c}8.61 \pm 0.56 \\
8.69 \\
(8.24 ; 9.02)\end{array}$ & $\begin{array}{c}8.67 \pm 0.83 \\
8.89 \\
(8.18 ; 9.22)\end{array}$ & $\begin{array}{c}9.83 \pm 0.66 \\
9.78 \\
(9.47 ; 10.07)\end{array}$ & $\begin{array}{l}p 1-p 2<0.0001 \\
p 1-p 3<0.0001 \\
p 1-p 4<0.0001 \\
p 2-p 4<0.0001 \\
p 3-p 4<0.0001\end{array}$ \\
\hline $\begin{array}{c}\text { Обобщенный показатель } \\
\text { вязкости, } \mathrm{Pa} \cdot \mathrm{s}\end{array}$ & $\begin{array}{c}5.79 \pm 0.73 \\
5.93 \\
(5.11 ; 6.17)\end{array}$ & $\begin{array}{c}7.06 \pm 0.32 \\
7.14 \\
(6.83 ; 7.30)\end{array}$ & $\begin{array}{c}6.96 \pm 0.46 \\
6.94 \\
(6.37 ; 7.31)\end{array}$ & $\begin{array}{c}7.60 \pm 0.37 \\
7.64 \\
(7.32 ; 7.90)\end{array}$ & $\begin{array}{l}p 1-p 2<0.0001 \\
p 1-p 3<0.0001 \\
p 1-p 4<0.0001 \\
p 2-p 4<0.0001 \\
p 3-p 4<0.0001\end{array}$ \\
\hline
\end{tabular}


Таблица 1 (продолжение).

\begin{tabular}{|c|c|c|c|c|c|}
\hline Показатель & (1) & (2) & (3) & (4) & $p$ \\
\hline $\begin{array}{l}\text { Индекс агрегации } E r \\
\text { на } 1 \cdot 10^{6} \mathrm{~Hz} \text {, arb. units }\end{array}$ & $\begin{array}{c}0.023 \pm 0.052 \\
0.015 \\
(0.01 ; 0.018)\end{array}$ & $\begin{array}{c}0.023 \pm 0.011 \\
0.021 \\
(0.014 ; 0.03)\end{array}$ & $\begin{array}{c}0.047 \pm 0.04 \\
0.045 \\
(0.023 ; 0.054)\end{array}$ & $\begin{array}{c}0.079 \pm 0.08 \\
0.059 \\
(0.033 ; 0.069)\end{array}$ & $\begin{aligned} p 1-p 2 & =0.009 \\
p 1-p 3 & <0.0001 \\
p 1-p 4 & <0.0001 \\
p 2-p 4 & <0.0001 \\
p 3-p 4 & <0.0001\end{aligned}$ \\
\hline $\begin{array}{l}\text { Индекс агрегации } E r \\
\text { на } 5 \cdot 10^{5} \mathrm{~Hz} \text {, arb. units }\end{array}$ & $\begin{array}{c}0.023 \pm 0.052 \\
0.012 \\
(0.011 ; 0.017)\end{array}$ & $\begin{array}{c}0.023 \pm 0.011 \\
0.02 \\
(0.013 ; 0.029)\end{array}$ & $\begin{array}{c}0.049 \pm 0.045 \\
0.047 \\
(0.021 ; 0.055)\end{array}$ & $\begin{array}{c}0.081 \pm 0.093 \\
0.063 \\
(0.03 ; 0.074)\end{array}$ & $\begin{array}{c}p 1-p 2=0.006 \\
p 1-p 3<0.0001 \\
p 1-p 4<0.0001 \\
p 2-p 3<0.0001 \\
p 2-p 4<0.0001 \\
p 3-p 4<0.001\end{array}$ \\
\hline $\begin{array}{l}\text { Индекс агрегации } E r \\
\text { на } 1 \cdot 10^{5} \mathrm{~Hz} \text {, arb. units }\end{array}$ & $\begin{array}{c}0.025 \pm 0.049 \\
0.012 \\
(0.01 ; 0.015)\end{array}$ & $\begin{array}{c}0.023 \pm 0.011 \\
0.022 \\
(0.014 ; 0.03)\end{array}$ & $\begin{array}{c}0.051 \pm 0.054 \\
0.046 \\
(0.026 ; 0.059)\end{array}$ & $\begin{array}{c}0.091 \pm 0.11 \\
0.066 \\
(0.034 ; 0.074)\end{array}$ & $\begin{array}{c}p 1-p 2<0.01 \\
p 1-p 3<0.0001 \\
p 1-p 4<0.0001 \\
p 2-p 3<0.0001 \\
p 2-p 4<0.0001 \\
p 3-p 4<0.0001\end{array}$ \\
\hline $\begin{array}{l}\text { Индекс агрегации } E r \\
\text { на } 5 \cdot 10^{4} \mathrm{~Hz} \text {, arb. units }\end{array}$ & $\begin{array}{c}0.026 \pm 0.058 \\
0.013 \\
(0.011 ; 0.015)\end{array}$ & $\begin{array}{c}0.025 \pm 0.014 \\
0.02 \\
(0.015 ; 0.031)\end{array}$ & $\begin{array}{c}0.055 \pm 0.06 \\
0.047 \\
(0.023 ; 0.058)\end{array}$ & $\begin{array}{c}0.101 \pm 0.128 \\
0.067 \\
(0.038 ; 0.073)\end{array}$ & $\begin{array}{l}p 1-p 2=0.004 \\
p 1-p 3<0.0001 \\
p 1-p 4<0.0001 \\
p 2-p 3<0.0001 \\
p 2-p 4<0.0001 \\
p 3-p 4<0.0001\end{array}$ \\
\hline $\begin{array}{c}\text { Индекс деструкции } E r \\
\text { на } 1 \cdot 10^{6} \mathrm{~Hz}, \%\end{array}$ & $\begin{array}{c}0.086 \pm 0.28 \\
0.0001 \\
(0.00014 ; 0.00019)\end{array}$ & $\begin{array}{c}0.52 \pm 1.59 \\
0.0001 \\
(0.00013 ; 0.00018)\end{array}$ & $\begin{array}{c}0.37 \pm 1.31 \\
0.00013 \\
(0.0001 ; 0.00015)\end{array}$ & $\begin{array}{c}1.34 \pm 1.83 \\
0.00014 \\
(0.0001 ; 3.10)\end{array}$ & $\begin{array}{c}p 1-p 4<0.0001 \\
p 2-p 4=0.033 \\
p 3-p 4<0.0001 \\
\end{array}$ \\
\hline $\begin{array}{c}\text { Индекс деструкции } E r \\
\text { на } 5 \cdot 10^{5} \mathrm{~Hz}, \%\end{array}$ & $\begin{array}{c}0.11 \pm 0.32 \\
0.0001 \\
(0.00011 ; 0.00017)\end{array}$ & $\begin{array}{c}0.73 \pm 1.49 \\
0.00010 \\
(0.00012 ; 0.00017)\end{array}$ & $\begin{array}{c}0.34 \pm 0.98 \\
0.00012 \\
(0.0001 ; 0.00016)\end{array}$ & $\begin{array}{c}1.24 \pm 1.57 \\
0.00014 \\
(0.0001 ; 2.7)\end{array}$ & $\begin{array}{c}p 1-p 4<0.001 \\
p 3-p 4<0.0001\end{array}$ \\
\hline $\begin{array}{c}\text { Индекс деструкции } E r \\
\text { на } 1 \cdot 10^{5} \mathrm{~Hz}, \%\end{array}$ & $\begin{array}{c}0.00012 \pm 0.000001 \\
0.0001 \\
(0.00010 ; 0.00015)\end{array}$ & $\begin{array}{c}0.12 \pm 0.53 \\
0.0001 \\
(0.00012 ; 0.00015)\end{array}$ & $\begin{array}{c}0.075 \pm 0.42 \\
0.00012 \\
(0.00011 ; 0.00016)\end{array}$ & $\begin{array}{c}0.60 \pm 1.34 \\
0.00014 \\
(0.0001 ; 0.00017)\end{array}$ & $\begin{array}{l}p 1-p 4<0.001 \\
p 2-p 4=0.098 \\
p 3-p 4<0.001\end{array}$ \\
\hline $\begin{array}{c}\text { Индекс деструкции } E r \\
\text { на } 5 \cdot 10^{4} \mathrm{~Hz}, \%\end{array}$ & $\begin{array}{c}0.029 \pm 0.16 \\
0.0001 \\
(0.00011 ; 0.00016)\end{array}$ & $\begin{array}{c}0.51 \pm 1.22 \\
0.0001 \\
(0.00011 ; 0.00015)\end{array}$ & $\begin{array}{c}0.12 \pm 0.58 \\
0.00012 \\
(0.00010 ; 0.00015)\end{array}$ & $\begin{array}{c}0.25 \pm 0.76 \\
0.00013 \\
(0.00010 ; 0.00016)\end{array}$ & $\begin{array}{l}p 1-p 2=0.076 \\
p 2-p 3=0.094\end{array}$ \\
\hline
\end{tabular}

$\left(8.61 \pm 0.56 \cdot 10^{-6} \mathrm{~N} / \mathrm{m}\right.$ против $6.56 \pm 0.91 \cdot 10^{-6} \mathrm{~N} / \mathrm{m}$ у здоровых, $p<0.0001)$. Уровни данного показателя у больных с ранними стадиями КРР и полипами были сопоставимы, высоко достоверное увеличение жесткости отмечено лишь на поздних стадиях КРР $(p<0.0001)$. Подобные закономерности выявлены в отношении обобщённого показателя вязкости: достоверное увеличение у больных с полипами и ранними стадиями КРР по сравнению со здоровыми лицами $(p<0.0001)$, отсутствие значимых различий между группами с полипами и ранними стадиями и достоверное нарастание показателя в поздние стадии КРР, отличное от всех вышеописанных групп $(p<0.0001)$.

Индекс агрегации был достоверно выше у лиц с полипами и КРР на всех частотах диапазона, чем таковой у здоровых лиц $(p=0.0001-0.009)$, причем ранние стадии КРР оказались ассоциированы с достоверным нарастанием данного показателя как по сравнению со здоровыми $(p<0.0001)$, так и по сравнению с пациентами с полипами $(p=0.009-0.01)$. Следует отметить значительное повышение склонности к агрегации на поздних стадиях заболевания по сравнению с ранними, особенно заметное на низких частотах электрического поля $\left(1 \cdot 10^{5}, 5 \cdot 10^{4} \mathrm{~Hz}, p<0.0001\right)$.

Наличие полипов и развитие КРР оказались ассоциированными с большей склонностью клеток к гемолизу преимущественно на высоких частотах диапазона $\left.1 \cdot 10^{6}-5 \cdot 10^{5} \mathrm{~Hz}\right)$. Достоверное увеличение индекса деструкции у больных с КРР по сравнению со здоровыми выявлено лишь на $1 \cdot 10^{6}$ и $1 \cdot 10^{5} \mathrm{~Hz} \quad(p=0.018$ и 
Таблица 1 (продолжение).

\begin{tabular}{|c|c|c|c|c|c|}
\hline Показатель & (1) & (2) & (3) & (4) & $p$ \\
\hline $\begin{array}{c}\text { Поляризуемость } \\
\text { на } 1 \cdot 10^{6} \mathrm{~Hz}, \times 10^{-15}, \mathrm{~m}^{3}\end{array}$ & $\begin{array}{c}5.48 \pm 1.01 \\
5.3 \\
(4.98 ; 6.2)\end{array}$ & $\begin{array}{c}4.27 \pm 0.62 \\
4.27 \\
(3.98 ; 4.82)\end{array}$ & $\begin{array}{c}4.61 \pm 1.30 \\
4.65 \\
(3.69 ; 5.46)\end{array}$ & $\begin{array}{c}3.48 \pm 0.97 \\
3.28 \\
(2.89 ; 4.02)\end{array}$ & $\begin{array}{l}p 1-p 2<0.0001 \\
p 1-p 4<0.0001 \\
p 1-p 4<0.0001 \\
p 1-p 4<0.0001 \\
p 1-p 4<0.0001\end{array}$ \\
\hline $\begin{array}{c}\text { Поляризуемость } \\
\text { на } 5 \cdot 10^{5} \mathrm{~Hz}, \times 10^{-15}, \mathrm{~m}^{3}\end{array}$ & $\begin{array}{c}3.42 \pm 0.85 \\
3.25 \\
(2.78 ; 4.23)\end{array}$ & $\begin{array}{c}2.69 \pm 0.61 \\
2.81 \\
(2.18 ; 3.09)\end{array}$ & $\begin{array}{c}3.35 \pm 1.22 \\
3.12 \\
(2.44 ; 3.99)\end{array}$ & $\begin{array}{c}2.59 \pm 0.79 \\
2.54 \\
(2.15 ; 2.98)\end{array}$ & $\begin{array}{c}p 1-p 2=0.003 \\
p 1-p 4<0.0001 \\
p 2-p 3=0.044 \\
p 3-p 4<0.0001\end{array}$ \\
\hline $\begin{array}{c}\text { Поляризуемость } \\
\text { на } 5 \cdot 10^{4} \mathrm{~Hz}, \times 10^{-15}, \mathrm{~m}^{3}\end{array}$ & $\begin{array}{c}-3.86 \pm 0.76 \\
-3.87 \\
(-3.21 ;-4.25)\end{array}$ & $\begin{array}{c}-2.56 \pm 0.47 \\
-2.67 \\
(-2.21 ;-2.99)\end{array}$ & $\begin{array}{c}-2.87 \pm 1.12 \\
-2.69 \\
(-2.09 ;-3.59)\end{array}$ & $\begin{array}{c}-2.72 \pm 0.89 \\
-2.67 \\
(-2.07 ;-3.14)\end{array}$ & $\begin{array}{c}p 1-p 2<0.0001 \\
p 1-p 3<0.001 \\
p 1-p 4<0.0001\end{array}$ \\
\hline Относительная поляризуемость & $\begin{array}{c}0.71 \pm 0.08 \\
0.72 \\
(0.67 ; 0.76)\end{array}$ & $\begin{array}{c}0.59 \pm 0.07 \\
0.62 \\
(0.53 ; 0.64)\end{array}$ & $\begin{array}{c}0.55 \pm 0.14 \\
0.56 \\
(0.46 ; 0.61)\end{array}$ & $\begin{array}{c}0.69 \pm 0.16 \\
0.67 \\
(0.56 ; 0.82)\end{array}$ & $\begin{array}{c}p 1-p 2<0.0001 \\
p 1-p 3<0.0001 \\
p 2-p 3=0.039 \\
p 2-p 4=0.011 \\
p 3-p 4<0.0001\end{array}$ \\
\hline Электропроводность $\times 10^{-5}, \mathrm{~cm} / \mathrm{m}$ & $\begin{array}{c}4.98 \pm 0.60 \\
4.88 \\
(4.66 ; 5.39)\end{array}$ & $\begin{array}{c}6.29 \pm 0.43 \\
6.14 \\
(5.92 ; 6.54)\end{array}$ & $\begin{array}{c}6.63 \pm 1.06 \\
6.25 \\
(5.81 ; 7.14)\end{array}$ & $\begin{array}{c}8.24 \pm 1.11 \\
8.56 \\
(7.41 ; 9.30)\end{array}$ & $\begin{array}{l}p 1-p 2<0.0001 \\
p 1-p 3<0.0001 \\
p 1-p 4<0.0001 \\
p 2-p 4<0.0001 \\
p 3-p 4<0.0001\end{array}$ \\
\hline $\begin{array}{c}\text { Емкость клеточной } \\
\text { мембраны } \times 10^{-14}, \Phi\end{array}$ & $\begin{array}{c}7.16 \pm 0.56 \\
7.24 \\
(6.59 ; 7.55)\end{array}$ & $\begin{array}{c}4.84 \pm 1.58 \\
5.39 \\
(3.67 ; 6.09)\end{array}$ & $\begin{array}{c}5.77 \pm 1.83 \\
5.92 \\
(4.66 ; 7.08)\end{array}$ & $\begin{array}{c}2.75 \pm 2.07 \\
2.28 \\
(0.94 ; 3.67)\end{array}$ & $\begin{array}{c}p 1-p 2<0.0001 \\
p 1-p 3=0.039 \\
p 1-p 4<0.0001 \\
p 2-p 3=0.027 \\
p 2-p 4<0.0001 \\
p 3-p 4<0.0001\end{array}$ \\
\hline $\begin{array}{c}\text { Скорость движения } E r \\
\text { к электродам, } \mu \mathrm{m} / \mathrm{s}\end{array}$ & $\begin{array}{c}7.81 \pm 0.10 \\
7.9 \\
(7.2 ; 8.6)\end{array}$ & $\begin{array}{c}5.89 \pm 0.85 \\
6.0 \\
(5.8 ; 6.4)\end{array}$ & $\begin{array}{c}5.38 \pm 1.42 \\
5.3 \\
(4.2 ; 6.6)\end{array}$ & $\begin{array}{c}3.77 \pm 1.09 \\
3.7 \\
(2.9 ; 4.2)\end{array}$ & $\begin{array}{l}p 1-p 2<0.0001 \\
p 1-p 3<0.0001 \\
p 1-p 4<0.0001 \\
p 2-p 4<0.0001 \\
p 3-p 4<0.0001\end{array}$ \\
\hline $\begin{array}{c}\text { Положение равновесной } \\
\text { частоты } \times 10^{6}, \mathrm{~Hz}\end{array}$ & $\begin{array}{c}0.49 \pm 0.067 \\
0.51 \\
(0.43 ; 0.54)\end{array}$ & $\begin{array}{c}0.66 \pm 0.23 \\
0.65 \\
(0.54 ; 0.84)\end{array}$ & $\begin{array}{c}0.78 \pm 1.23 \\
0.39 \\
(0.31 ; 0.74)\end{array}$ & $\begin{array}{c}1.76 \pm 1.39 \\
1.22 \\
(0.72 ; 2.78)\end{array}$ & $\begin{array}{c}p 1-p 2<0.001 \\
p 1-p 3=0.015 \\
p 1-p 4<0.0001 \\
p 2-p 4<0.001 \\
p 3-p 4<0.0001\end{array}$ \\
\hline Дипольный момент $\times 10^{-21}, \mathrm{Q} \cdot \mathrm{m}$ & $\begin{array}{c}7.56 \pm 1.12 \\
7.32 \\
(6.97 ; 8.14)\end{array}$ & $\begin{array}{c}5.59 \pm 0.51 \\
5.63 \\
(5.14 ; 6.07)\end{array}$ & $\begin{array}{c}6.87 \pm 1.58 \\
7.12 \\
(5.24 ; 8.22)\end{array}$ & $\begin{array}{c}4.87 \pm 1.1 \\
4.97 \\
(3.99 ; 5.64)\end{array}$ & $\begin{array}{c}p 1-p 2<0.0001 \\
p 1-p 4<0.0001 \\
p 2-p 3=0.002 \\
p 2-p 4=0.006 \\
p 3-p 4<0.0001\end{array}$ \\
\hline
\end{tabular}

Примечание. В ячейках столбцов 1-4 таблицы указаны (сверху вниз): $M \pm S D, M-$ средняя арифметическая вариационного ряда, $S D-$ среднеквадратическое отклонение, $M e$ - медиана, в скобках: $25 \%$; $7 \%-25$ и 75 перцентили.

$p<0.029)$. При этом достоверных различий в уровне гемолиза у пациентов с полипами и здоровых лиц, как и больных с КРР, не выявлено. Разделение на стадии КРР позволило выявить значимое нарастание доли гемолизированных клеток именно на поздних стадиях заболевания, достоверно более высокое по сравнению как со здоровыми, больными с полипами, так и ранними стадиями $(p<0.0001-0.033)$. При наличии тенденций к увеличению индекса деструкции, при наличии полипов или ранних стадий КРР по сравнению со здоровыми различия не достигали уровня достоверности, вероятно, из-за большого разброса значений данного показателя. 
Поляризуемость на всех частотах электрического поля у пациентов с полипами и КРР была достоверно ниже таковой у здоровых лиц $(p<0.0001-0.001)$. При этом на высокой частоте $1 \cdot 10^{6} \mathrm{~Hz}$ и низкой частоте $1 \cdot 10^{5} \mathrm{~Hz}$ выявлены достоверные различия между группами пациентов с полипами и общей группой пациентов с КРР $\left(p<0.001\right.$ - для $1 \cdot 10^{6} \mathrm{~Hz} ; p=0.018$ - для $\left.1 \cdot 10^{5} \mathrm{~Hz}\right)$. Ранние стадии КРР отличались от здоровых лиц по уровню поляризуемости на низкой частоте $5 \cdot 10^{4} \mathrm{~Hz}(p<0.001)$ с тенденцией на высокой частоте $1 \cdot 10^{6} \mathrm{~Hz}(p=0.061)$ и от пациентов с полипами лишь на двух частотах: $5 \cdot 10^{5} \mathrm{~Hz}-p=0.044$ и $1 \cdot 10^{5} \mathrm{~Hz}-$ $p=0.032$. На поздних стадиях КРР данный параметр был достоверно ниже, чем на ранних на высоких часто$\operatorname{tax}\left(1 \cdot 10^{6}, 5 \cdot 10^{5} \mathrm{~Hz}, p<0.0001\right)$.

Относительная поляризуемость у больных с полипами и больных с КРР (общая группа) оказалась достоверно ниже таковой, чем у здоровых лиц $(p<0.0001)$. При этом ранние стадии достоверно отличались не только от контрольной группы $(p<0.0001)$, но и пациентов с полипами $(p<0.039)$. Уровень данного параметра был значимо отличен между ранними и поздними стадиями KРP $(p<0.0001)$.

Показатель электропроводности оказался достоверно выше при наличии полипов и КРР, чем данный параметр у здоровых лиц $(p<0.0001)$. При этом пациенты с КРР имели достоверно более высокую электропроводность, чем больные с полипами $(p<0.0001)$. Вместе с тем выявлено, что на ранних стадиях уровень данного параметра был сопоставим с таковым у больных с полипами, достоверно отличаясь от здоровых $(p<0.0001)$. А поздние стадии оказались ассоциированы со значительным увеличением электропроводности по сравнению со всеми другими изучаемыми группами больных $\left((8.24 \pm 1.11) \cdot 10^{-5} \mathrm{~cm} / \mathrm{m}\right.$ на поздних стадиях против $(4.98 \pm 0.60) \cdot 10^{-5} \mathrm{~cm} / \mathrm{m}$ у здоровых, $p<0.0001$, против $(6.29 \pm 0.43) \cdot 10^{-5} \mathrm{~cm} / \mathrm{m}$ у пациентов с полипами, $p<0.001$, и против $(6.63 \pm 1.06) \cdot 10^{-5} \mathrm{~cm} / \mathrm{m}$ на ранних стадиях КРР, $p<0.0001)$.

Емкость клеточной мембраны при наличии полипов и КРР была достоверно ниже, чем у здоровых лиц $(p<0.0001)$; при этом группа больных с полипами и общая группа пациентов с КРР были сопоставимы между собой по данному показателю. Различия выявились при рассмотрении ранних и поздних стадий отдельно: емкость на ранних стадиях КРР была выше, чем у пациентов с полипами, но достоверно ниже таковой у здоровых лиц $\left((5.77 \pm 1.83) \cdot 10^{-14} \Phi\right.$ на ранних стадиях против $(4.84 \pm 1.58) \cdot 10^{-14} \Phi$ при полипах, $p=0.027$, и против $(7.16 \pm 0.56) \cdot 10-{ }^{14} \Phi$ у здоровых, $\left.p=0.039\right)$. Установлено значимое снижение ёмкости на поздних стадиях КРР $\left((2.75 \pm 2.07) \cdot 10^{-14} \Phi\right)$, достоверно отличимое как от ранних стадий $(p<0.0001)$, так и от пациентов с полипами $(p<0.0001)$.

Скорость движения эритроцитов к электродам достоверно снижалась по направлению ,здоровые-больные с полипами-больные с КРР“, причём последние группы также значимо отличались по данному параметру $(p<0.0001)$. В ранних стадиях КРР клетки двигались медленнее к электродам, чем у пациентов с полипами и здоровых лиц $(p<0.0001)$. Выявлено существенное снижение скорости движения клеток в поздних стадиях КРР по сравнению с ранними $(3.77 \pm 1.09 \mu \mathrm{m} / \mathrm{s}$ в поздние стадии против $5.38 \pm 1.42 \mu \mathrm{m} / \mathrm{s}$ в ранние, $p<0.0001)$.

Наличие патологического процесса было ассоциировано со смещением равновесной частоты в высокочастотный диапазон по сравнению со здоровыми лицами $(p<0.001-0.05)$. При этом именно на поздних стадиях КРР этот сдвиг становился максимальным, достоверно отличаясь не только от здоровых лиц $\left((1.76 \pm 1.39) \cdot 10^{6} \mathrm{~Hz}\right.$ на поздних стадиях против $(0.49 \pm 0.067) \cdot 10^{6} \mathrm{~Hz}$ у здоровых лиц, $p<0.0001)$, но и от больных с полипами $\left((0.66 \pm 0.23) \cdot 10^{6} \mathrm{~Hz}, p<0.001\right)$ и ранними стадиями KРP $\left((0.78 \pm 1.23) \cdot 10^{6} \mathrm{~Hz}, p<0.0001\right)$.

Общий тренд к снижению величины дипольного момента у лиц с полипами и больных с КРР (общая группа) в отличие от здоровых лиц $(p<0.0001)$ при рассмотрении ранних и поздних стадий отдельно позволил выявить достоверное снижение показателя в терминальные стадии КРР в отличие от больных с полипами $(p=0.006)$ и ранними стадиями $(p<0.0001)$.

Выполненное исследование демонстрирует возможности выявления функциональных изменений клеток красной крови по ходу прогрессирования опухолевого процесса на примере КРР. Широкий ряд измеряемых параметров эритроцитов с различной их вариацией в ходе развития патологического процесса в организме позволяет использовать их и в целом метод ДЭФ для диагностики стадий развития онкологического процесса. Перед описанием предложенных в работе „диагностических панелей“ представляется целесообразным проанализировать возможные механизмы, влияющие на электрические и вязкоупругие параметры эритроцитов.

Параметры эритроцитов, изученные с использованием метода диэлектрофореза, отражают „тонкие“ ранние изменения, происходящие по оси „здоровые-предракрак“, при этом развитие злокачественного опухолевого процесса приводит к деполяризации эритроцитов. Следует отметить, что амплитудно-частотные характеристики клетки в НПЭП являются хорошим индикатором физико-химических свойств ее мембраны и цитоплазмы, а также отражают состояние ее биологической активности.

Наблюдаемые изменения электрических и вязкоупругих параметров эритроцитов, вероятно, связаны с изменениями структуры их мембран в связи с адсорбцией крупномолекулярных белков, иммуноглобулинов, иммунных комплексов, которые „экранируют“ отрицательный заряд клетки, снижая ее скорость движения к электродам, дипольный момент и снижая емкость мембран [14,18-20]. С другой стороны, изменяется 
состав, перераспределение в структуре мембраны холестерина, фосфолипидов с нарастанием лизофракций, снижается уровень арахидоновой и повышаются уровни олеиновой, стеариновой жирных кислот, что, возможно, сказывается на обобщенном показателе вязкости и электропроводности $[18,21]$. Нарастание количества трансформированных клеток под действием опухолевого процесса сопровождается нарушениями ультраструктуры клеток, выражающимися в перераспределении в цитоплазме гемоглобина, усилением образования эндои экзовезикул, разрыхлением, уплотнением, деструкцией цитолеммы и т.д., что влияет на обобщенный показатель жесткости и амплитуду деформации [18]. Нарушение формы и снижение деформируемости клеток красной крови, вероятно, возникают в результате разнообразных воздействий на мембрану (гипоксических, иммунных, токсических), имеющих место и при развитии опухолевого процесса $[18,21,22]$. Сниженная поляризуемость отражает низкую резистентность клеток красной крови, возможно, на фоне угнетающего влияния опухоли на эритропоэз через целый комплекс цитокинов [23,24]. Это приводит к склонности клеток к гемолизу на разных частотах особенно в продвинутых стадиях КРР, что усугубляет склонность к агрегации, микроциркуляторным нарушениям [25]. С другой стороны, неопластический рост сопровождается выраженными серологическими перестройками мембран эритроцитов и появлением в крови аутоантител, которые могут быть причиной гемолитических состояний [26].

Следующим этапом настоящего исследования оказалось создание SHAP-графиков для моделей, позволяющих провести дифференцирование в парах групп пациентов ,пациенты с аденоматозными полипами vs здоровые лица“, „пациенты с ранними стадиями КРР vs здоровые лица“, „пациенты с аденоматозными полипами $v s$ ранние стадии КРР“, „ранние $v s$ поздние стадии КРР“.

В модели М1 для различения пациентов с аденоматозными полипами от здоровых лиц (рис. 2) (группа сравнения - positive класс, группа с полипами negative класс) в первой десятке наиболее значимых параметров оказались меньшие значения параметров степени деформации эритроцитов на частоте $5 \cdot 10^{5} \mathrm{~Hz}$ и амплитуды деформации на частоте $10^{6} \mathrm{~Hz}$, дипольного момента и доли дискоцитов (ранги 1, 2, 5 и 6), которые характерны для группы пациентов с полипами, а большие значения - для лиц контрольной группы.

В модели М2, позволяющей отличить пациентов с ранними стадиями КРР от здоровых лиц (рис. 3) (группа сравнения - positive класс, группа с ранними стадиями КРР - negative класс) скорость движения эритроцитов, доля деформированных клеток и обобщенная жесткость являются наиболее значимыми параметрами, обеспечивающими основную дифференцирующую способность модели. При интерпретации значений для параметров „скорость движения эритроцитов“, „амплитуда деформации на частоте $10^{6} \mathrm{~Hz}^{6}$, „радиус эритроцита“ (на всех частотах электрического поля) наименьшие значения соответствуют ранним стадиям КРР, а большие контрольной группе в отличие от параметров „обобщенная жесткость и вязкость“, а также „индекс агрегации“ (на всех частотах), большие значения которых характерны для больных с КРР, а меньшие - для лиц группы сравнения. У параметров ,доля деформированных клеток“, „электропроводность“ и „относительная поляризуемость“, несмотря на их высокий ранг (2, 4 и 5 соответственно), однозначной интерпретируемости по значению параметров не наблюдается. Вероятно, высокий вклад обусловлен возможностью обрабатывать моделями различные сочетания значений параметров.

При анализе $S H A P$-графиков полученных моделей (M1 и M2) выявлен ряд наиболее информативных параметров со схожим характером дифференцирующей составляющей (соотношений больших и меньших значений). Это амплитуда и степень деформации (меньшие - negative), а также электропроводность и агрегация (меньшие - positive). Для других параметров такой однозначной интерпретации вклада получено не было. Вероятно, это отражение отсутствия значимых различий в части описательных статистик для диагностических групп и разного характера диагностируемого процесса.

Для модели М3 для различения пациентов с аденоматозными полипами от больных с ранними стадиями КРР (рис. 4) (группа с полипами - positive класс, группа с ранними стадиями КРР - negative класс) отмечен наибольший вклад значений радиуса эритроцита на всех частотах с единообразной логикой вклада: большие значения характерны для пациентов, имеющих полипы, меньшие значения - для пациентов с начальными стадиями КРР. Для значений индекса агрегации (на частотах от $1 \cdot 10^{5}$ до $1 \cdot 10^{6} \mathrm{~Hz}$ ) и поляризуемости (от $5 \cdot 10^{5}$ до $1 \cdot 10^{6} \mathrm{~Hz}$ ) выявлена другая логика интерпретации: меньшие значения характерны для пациентов, имеющих полипы, а большие - для пациентов с начальными стадиями КРР. Для параметра „доля дискоцитов“" такого единообразия в интерпретации не наблюдается, несмотря на достаточно сильный вклад параметра в общую оценку диагностической модели шестое место по значимости (после значений радиуса эритроцитов на разных частотах электрического поля).

Для модели M4 для дифференцирования пациентов с ранними стадиями от поздних стадий КРР (рис. 5) (группа с ранними стадиями КРР - positive класс, группа с поздними стадиями КРР - negative класс) характерен полиморфизм в интерпретации параметров. Для параметров „степень деформации эритроцитов на

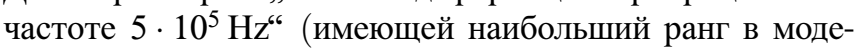
ли M4) и „поляризуемость на частоте $1 \cdot 10^{6} \mathrm{~Hz}^{6}$ (пятое место) меньшие значения параметров (синий цвет точек) характерны для больных с поздними стадиями КРР. Для показателей „обобщенная жесткость эритроцитов“, „радиус на частоте $1 \cdot 10^{5} \mathrm{~Hz}^{\text {“ }}$ и „индекс агрегации на $1 \cdot 10^{5} \mathrm{~Hz}^{6}$ (2, 3 и 4 ранги в рейтинге значимости вклада параметров соответственно), а также ,доля деформированных клеток“ и „электропроводность“ (7 и 


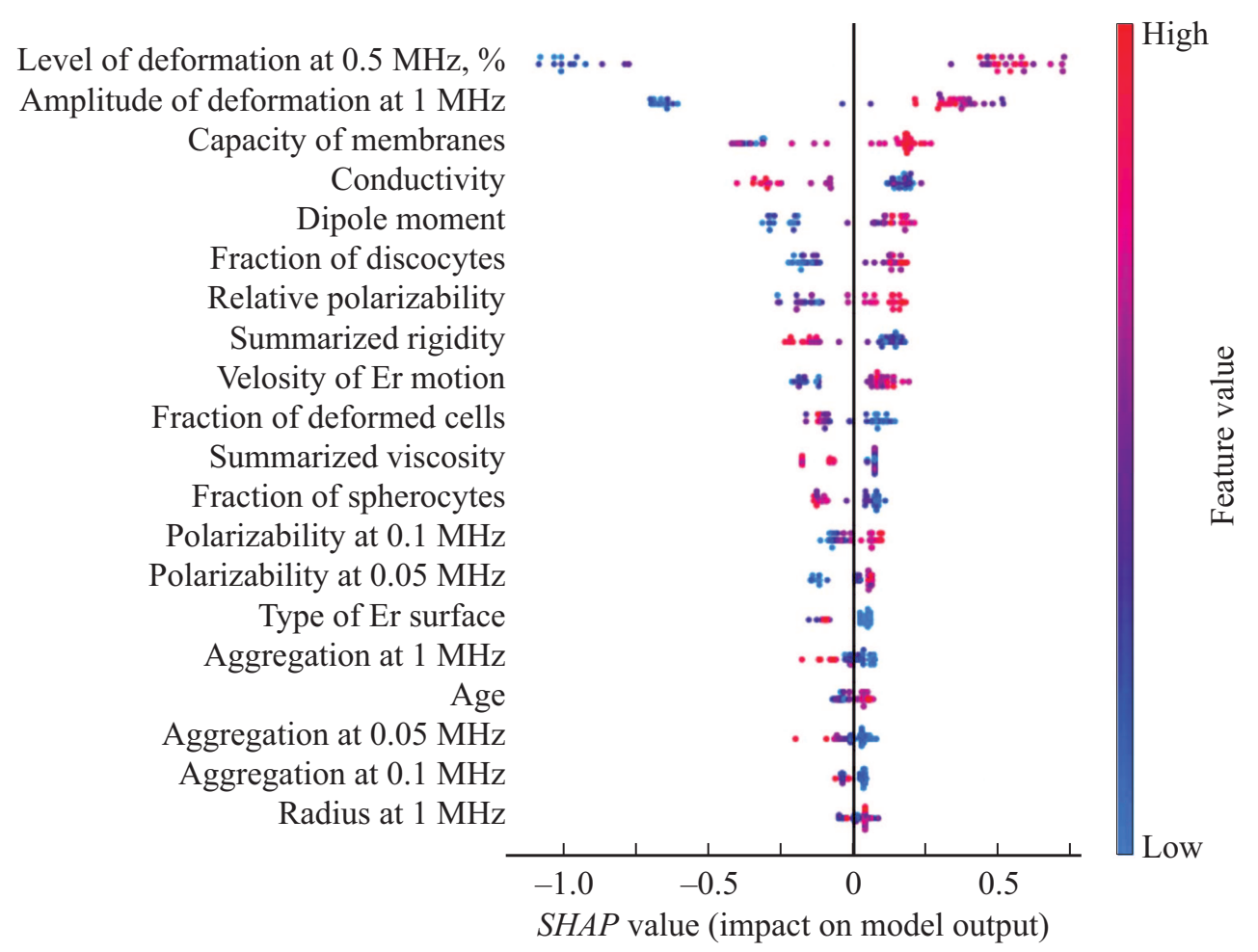

Рис. 2. График SHAP для диагностической модели, различающей пациентов с аденоматозными полипами (слева от вертикальной линии - negative) от группы здоровых (справа от вертикальной линии - positive).

Velosity of Er motion Fraction of deformed cells

Summarized rigidity Conductivity

Relative polarizability Amplitude of deformation at $1 \mathrm{MHz}$ Average radius Summarized viscosity Radius at $0.5 \mathrm{MHz}$ Aggregation at $0.05 \mathrm{MHz}$ Radius at $1 \mathrm{MHz}$

Radius at $0.1 \mathrm{MHz}$

Aggregation at $0.5 \mathrm{MHz}$

Radius at $0.05 \mathrm{MHz}$

Aggregation at $1 \mathrm{MHz}$

Aggregation at $0.1 \mathrm{MHz}$

Equilibrium frequency Level of deformation at $0.5 \mathrm{MHz}, \%$

Fraction of spherocytes Polarizability at $0.05 \mathrm{MHz}$

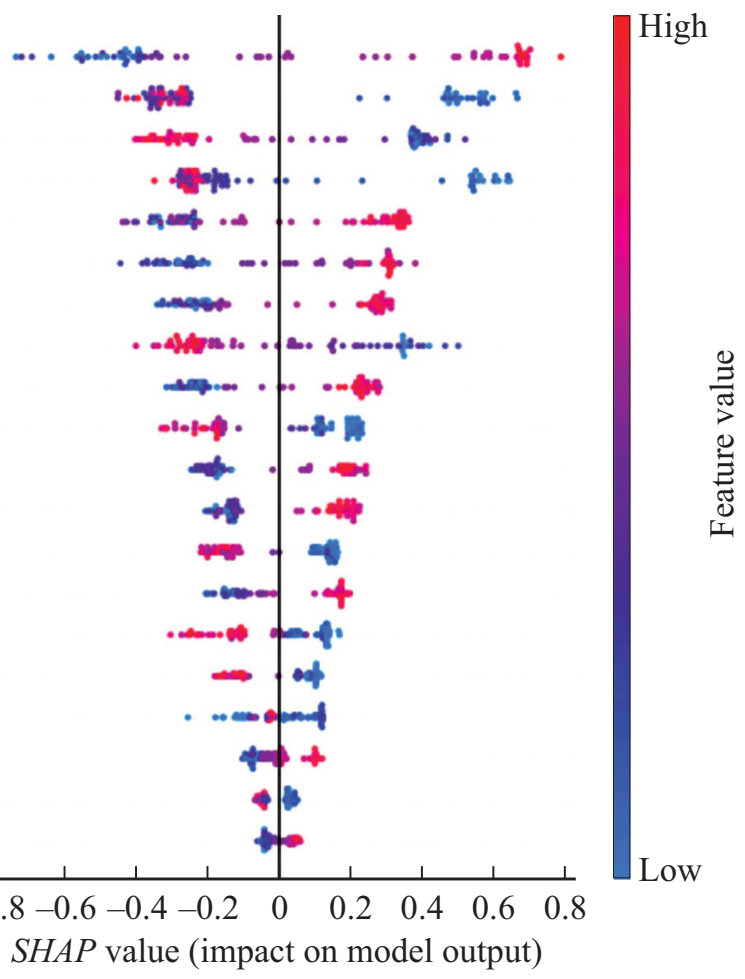

Рис. 3. График SHAP для диагностической модели, различающей пациентов с ранними стадиями КРP (слева от вертикальной линии - negative) от группы здоровых (справа от вертикальной линии - positive). 


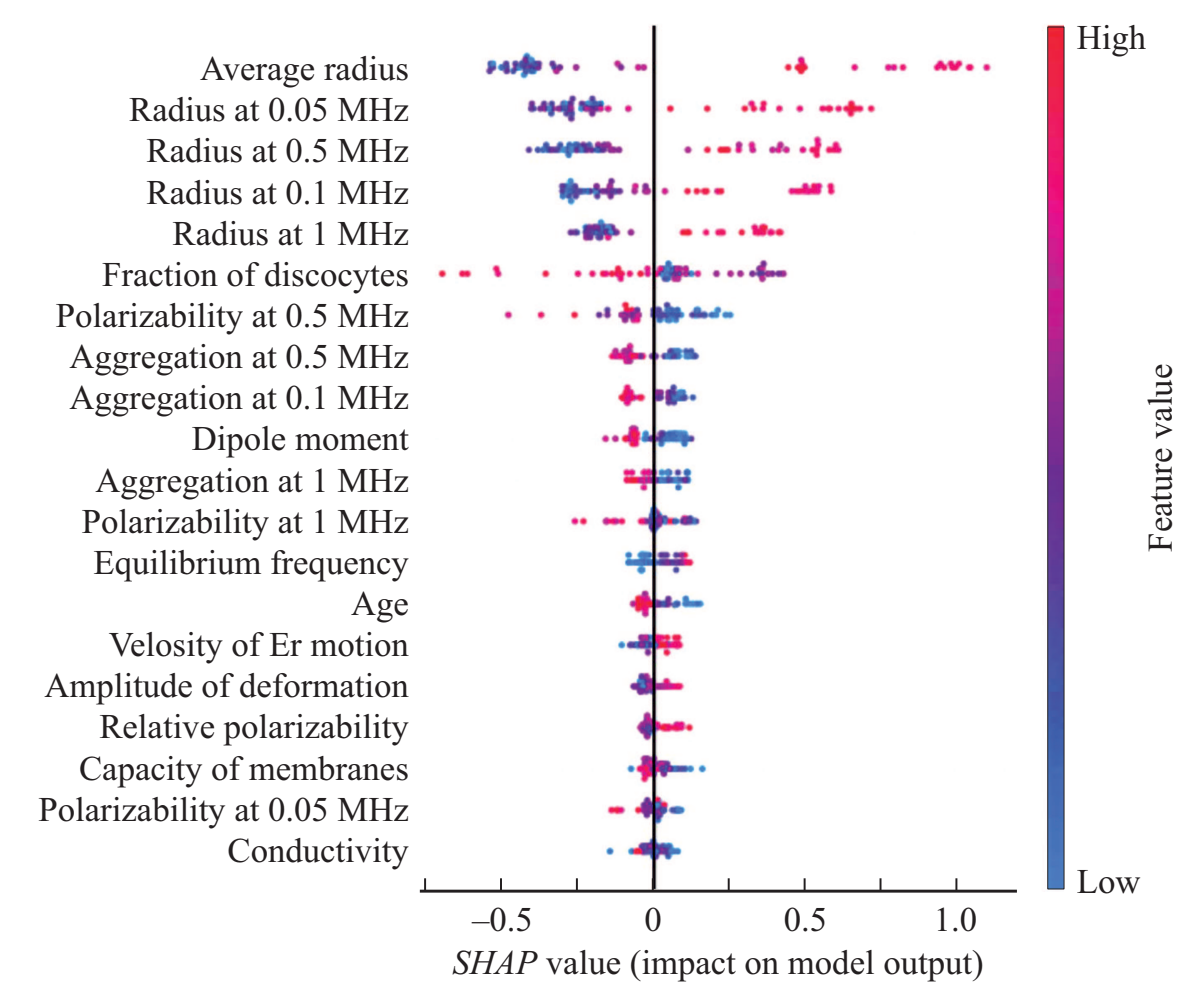

Рис. 4. График SHAP для диагностической модели, различающей пациентов с ранними стадиями КРР (слева от вертикальной линии - negative) от группы пациентов с аденоматозными полипами (справа от вертикальной линии - positive).

Level of deformation, \%

Summarized rigidity

Radius at $0.1 \mathrm{MHz}$

Aggregation at $0.1 \mathrm{MHz}$

Polarizability at $0.1 \mathrm{MHz}$

Aggregation at $1 \mathrm{MHz}$

Fraction of deformed cells

Conductivity

Aggregation at $0.05 \mathrm{MHz}$

Equilibrium frequency

Capacity of membranes

Relative polarizability

Polarizability at $0.5 \mathrm{MHz}$

Dipole moment

Amplitude of deformation

Polarizability at $0.05 \mathrm{MHz}$

Summarized viscosity

Radius at $0.05 \mathrm{MHz}$

Velosity of Er motion

Polarizability at $0.1 \mathrm{MHz}$

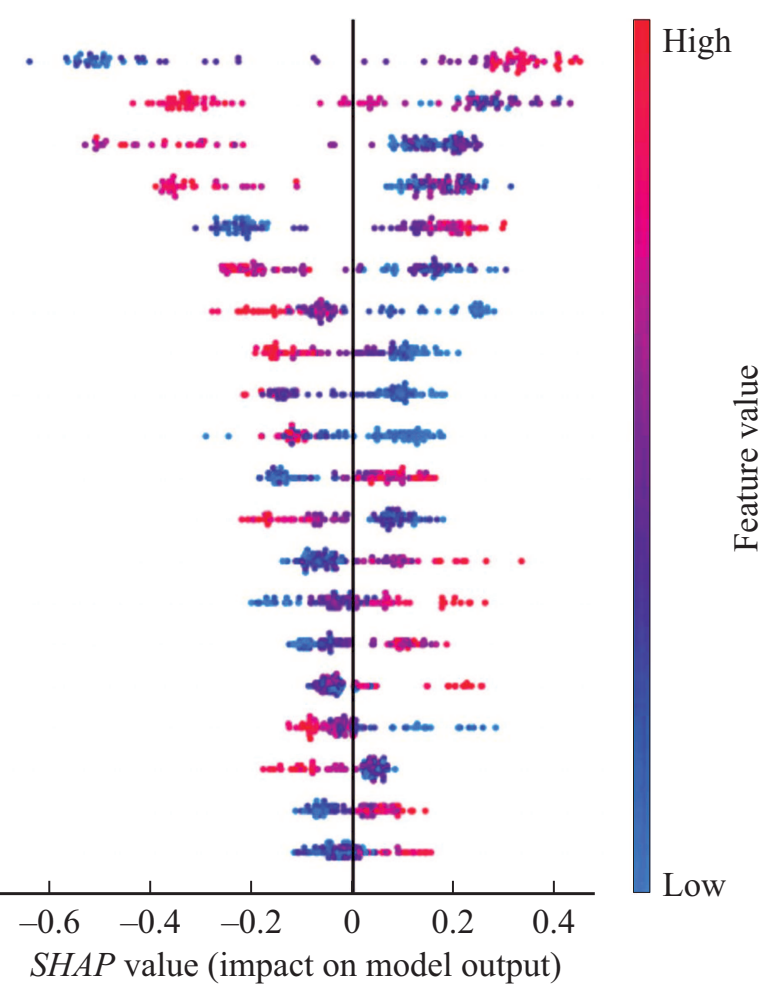

Рис. 5. График SHAP для диагностической модели, различающей пациентов с поздними стадиями КРР (слева от вертикальной линии - negative) от группы пациентов с ранними стадиями КРР (справа от вертикальной линии - positive). 
Таблица 2. Характеристики параметров диагностической точности моделей

\begin{tabular}{|c|c|c|c|c|c|c|}
\hline Модель & $\begin{array}{l}\text { Группа } \\
\text { negative }\end{array}$ & $\begin{array}{l}\text { Группа } \\
\text { positive }\end{array}$ & $\begin{array}{c}\text { Диагностическая } \\
\text { точность }\end{array}$ & $\begin{array}{c}\text { Специ- } \\
\text { фичность }\end{array}$ & $\begin{array}{l}\text { Чувстви- } \\
\text { тельность }\end{array}$ & $A U C$ \\
\hline M1 & $\begin{array}{c}\text { Группа с } \\
\text { полипами }\end{array}$ & $\begin{array}{c}\text { Группа } \\
\text { сравнения }\end{array}$ & 1.00 & 1.00 & 1.00 & 1.00 \\
\hline M2 & $\begin{array}{c}\text { Группа с } \\
\text { ранними } \\
\text { стадиями КРР }\end{array}$ & $\begin{array}{c}\text { Группа } \\
\text { сравнения }\end{array}$ & 1.00 & 1.00 & 1.00 & 1.00 \\
\hline M3 & $\begin{array}{c}\text { Группа с } \\
\text { ранними } \\
\text { стадиями КРР }\end{array}$ & $\begin{array}{c}\text { Группа с } \\
\text { полипами }\end{array}$ & 0.987 & 1.00 & 0.983 & 1.00 \\
\hline M4 & $\begin{array}{c}\text { Группа с } \\
\text { поздними } \\
\text { стадиями КРР }\end{array}$ & $\begin{array}{c}\text { Группа с } \\
\text { ранними } \\
\text { стадиями КРР }\end{array}$ & 0.919 & 0.93 & 0.909 & 0.982 \\
\hline
\end{tabular}

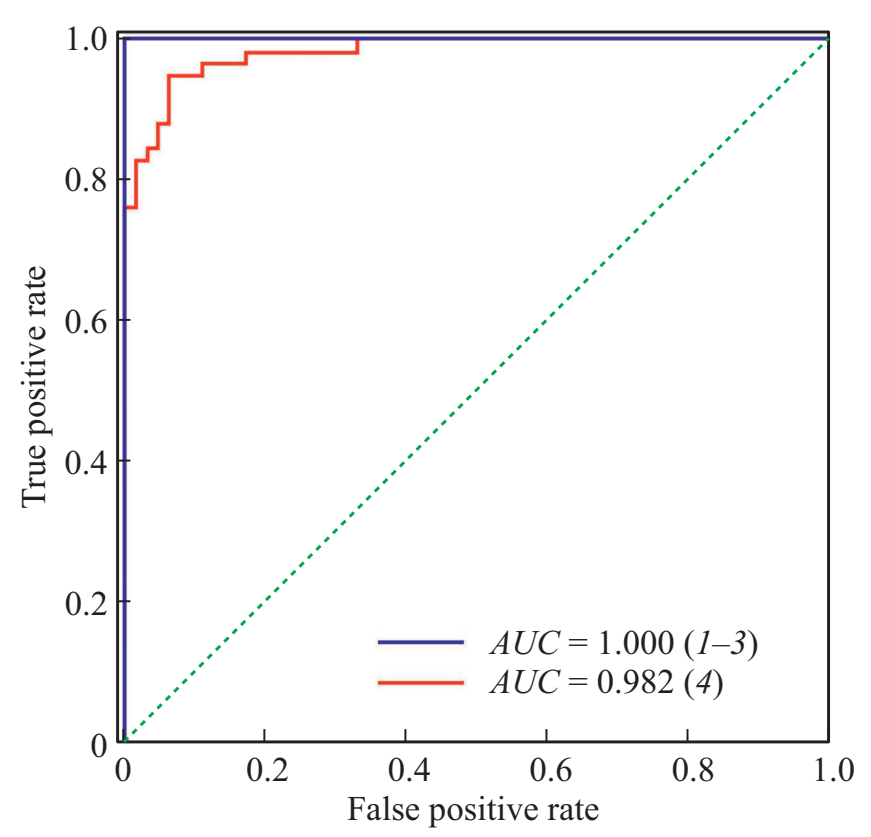

Pис. 6. ROC-анализ диагностической точности созданных моделей. 1-3 - совпадающие ROC-кривые для трех моделей: 1 - „полипы vs здоровые“, 2 - „ранние стадии КРР vs здоровые“, 3 - „полипы vs ранние стадии КРР“; 4 - „ранние стадии КРР $v s$ поздние стадии“.

8 ранг) работает другая логика интерпретации: большие значения (красный цвет точек) в основном характерны для пациентов с поздними стадиями КРР, но и среди пациентов с ранними стадиями изредка встречаются большие значения данного параметра (о чем свидетельствуют включения точек красного цвета в правой части графика).

Проведение ROC-анализа для выявления диагностической точности созданных моделей продемонстрировало очень высокий потенциал с $A U C$, равно 1 для трех первых моделей, и $A U C 0.982$ для четвертой модели, дифференцирующей ранние и поздние стадии КРР (рис. 6), что существенно превышает значения, полученные нами в более ранних моделях [8]. Параметры, отражающие диагностическую точность созданных моделей, представлены в табл. 2. Следует обратить внимание на $100 \%$ показатели чувствительности и специфичности при различении пациентов с аденоматозными полипами и ранними стадиями КРР от здоровых лиц, что важно для скрининга и ранней диагностики заболевания.

\section{Выводы}

Таким образом, эритроциты пациентов с КРР отличались от клеток красной крови здоровых лиц снижением доли дискоцитарных форм за счет увеличения сфероцитарных, с измененным характером поверхности, склонных к образованию агрегатов и деструкции на различных частотах НПЭП на фоне сниженных показателей поляризуемости, отражающих резистентность клеток с утолщенными мембранами со сниженным поверхностным зарядом и высокой способностью проводить электрический ток. По мере утяжеления заболевания (отличие ранних стадий от поздних) отмечено достоверное снижение среднего радиуса клеток, доли дискоцитов, амплитуды деформации на высоких частотах электрического поля, поляризуемости на всех частотах поля, емкости мембран, скорости движения клеток к электродам, величины дипольного момента и, напротив, значимое увеличение обобщенных показателей вязкости, жесткости, электропроводности, индексов агрегации и деструкции на всех частотах НПЭП. Продвинутые стадии КРР отличались от ранних значительным смещением равновесной частоты в высокочастотный диапазон.

У пациентов с аденоматозными полипами выявлены особенности электрических и вязкоупругих параметров эритроцитов по сравнению со здоровыми лицами, причем тренд изменений всех параметров совпадал с таковым у пациентов с КРР, что косвенно свидетельствует о предраковой природе аденоматозных полипов. 
Вместе с тем выявлены отличия параметров эритроцитов у пациентов с полипами от таковых у больных с ранними стадиями КРР: средний радиус клеток, поляризуемость на частоте $1 \cdot 10^{5} \mathrm{~Hz}$, относительная поляризуемость, скорость движения клеток к электродам у пациентов с полипами оказались достоверно выше, а доля дискоцитов, степень изменения амплитуды деформации на частоте $5 \cdot 10^{5} \mathrm{~Hz}$, индексы агрегации на всех частотах, поляризуемость на частоте $5 \cdot 10^{5} \mathrm{~Hz}$, емкость мембран, величина дипольного момента - ниже, чем на ранних стадиях КРР. Однако сдвиг равновесной частоты наблюдался уже в ранние стадии КРР, отличаясь от позиции у больных с полипами.

Учитывая специфику полученных данных (малые выборки большой размерности), для статистической обработки материала были использованы методы машинного обучения, которые применяют для создания диагностических моделей деревья решений. Построение SHAPграфиков на основе электрических и вязкоупругих параметров эритроцитов позволило достичь 100\% диагностической точности при различении пациентов с аденоматозными полипами, ранними стадиями КРР от здоровых лиц, 98.7\% точности - при дифференцировании пациентов с полипами от больных с ранними стадиями КРР, 91.9\% точности - при различении ранних и поздних стадий КРР. Полученные результаты демонстрируют высокий потенциал предложенного метода для скрининга и диагностики КРР.

\section{Соблюдение этических стандартов}

Все процедуры, выполненные в исследовании с участием людей, соответствуют этическим стандартам институционального и/или национального комитета по исследовательской этике и Хельсинкской декларации 1964 г. и ее последующим изменениям или сопоставимым нормам этики.

\section{Финансовая поддержка}

Работа выполнена в рамках темы „Эпидемиологический мониторинг состояния здоровья населения и изучение молекулярно-генетических и молекулярнобиологических механизмов развития распространенных терапевтических заболеваний в Сибири для совершенствования подходов к их диагностике, профилактике и лечению“ ГЗ № 0324-2018-0001, рег. № АААА-А17117112850280-2.

\section{Конфликт интересов}

Авторы заявляют, что у них нет конфликта интересов.

\section{Список литературы}

[1] Ferlay J., Soerjomataram I., Dikshit R., Eser S., Mathers C., Rebelo M., Parkin D.M., Forman D., Bray F. // Int. J. Cancer. 2015. V. 136. N 5. P. E359-E386.

[2] Di Lena M., Travaglio E., Altomare D.F. // World J. Gastroenterol. 2013. V. 19. N 12. P. 1855-1860.

[3] Garborg K., Holme O., Løberg M., Kalager M., Adami H.O., Bretthauer M. // Ann. Oncol. 2013. V. 24. N 8. P. 1963-1972.

[4] Stracci F., Zorzi M., Grazzini G. // Front. Public Health. 2014. V. 2. P. $210-219$.

[5] Кручинина М.В., Светлова И.О., Громов А.А., Кручинина Э.В., Генералов В.М., Кручинин В.Н., Яковина И.Н., Баннова Н.А. Факторы риска и методы скрининга колоректального рака: Учеб.-метод. пособие. Новосибирск: ООО „Офсет-ТМ“, 2019. 160 с.

[6] Kruchinina M.V., Gromov A.A., Generalov V.M., Kruchinin V.N., Shuvalov G.V., Minin O.V., Minin I.V. // Proc. SPIE 11065. Saratov Fall Meeting 2018: Optical and NanoTechnologies for Biology and Medicine. 2019. V. 110650V.

[7] Estridge B.H., Reynolds A.P. Basic Clinical Laboratory Techniques. Sixth Edition. NY., USA: Delmar, 2012. 907 p.

[8] Кручинина М.В., Прудникова Я.И., Громов А.А., Генералов В.М., Генералов К.В., Кручинин В.Н., Кручинина Э.В., Шувалов Г.В., Яковина И.Н., Баннова Н.А., Минин О.В., Минин И.В. // Опт. и спектр. 2019. Т. 126. В. 5. С. 652-657.

[9] Кручинина М.В., Стариков А.В., Громов А.А., Генералов B.M. // Терапия. 2016. № 3. В. 7. С. $40-47$.

[10] Sofaer H.R., Hoeting J.A., Jarnevich C.S. // Intelligent Systems Design and Appl. 2019. V. 941. P. 447-457.

[11] Ge Sh., Lu H., Li Q., Logan H.L., Dodd V., Bian J., Shenkman E.A., Guo Y. // American J. Health Behavior. 2019. V. 43. N 3. P. 635-647.

[12] Scott M. Lundberg, Su-In Lee A // 31st Conference on Neural Information Processing Systems (NIPS 2017). Long Beach, CA, USA.

https://papers.nips.cc/paper/2017/file/ 8a20a8621978632d76c43dfd28b67767-Paper.pdf

[13] Шувалов Г.В., Генералов К.В., Генералов В.М., Кручинина М.В., Коптев Е.С., Минин О.В., Минин И.В. // Изв. вузов. Физика. 2017. Т. 60. В. 11. С. 47-51.

[14] Генералов В.М., Кручинина М.В, Дурыманов А.Г., Медведев А.А., Сафатов А.С., Сергеев А.Н., Буряк Г.А., Курилович С.А., Громов А.А. Диэлектрофорез в диагностике инфекционных и неинфекционных заболеваний. Новосибирск: ЦЭРИС, 2011. 172 с.

[15] Минин И.В., Минин О.В. Микроскопное покровное стекло. Патент РФ 2672980. Опубл. 21.11.2018. Бюл. № 33.

[16] Kruchinina M.V., Gromov A.A., Prudnikova Y.I., Generalov V.M., Kruchinin V.N., Volodin V.A., Shuvalov G.V., Minin O.V., Shehovtsov S.V., Peltec S.E., Minin I.V. // IOP Conf. Series: Materials Science and Engineering. 2019. V. 516. P. 012017.

[17] Shuvalov G.V., Generalov K.V., Generalov V.M., Kruchinina M.V., Koptev E.S., Minin O.V., Minin I.V. // Russian Phys. J. 2018. V. 60. N 11. P. 1901-1904.

[18] Кручинина М.В., Кручинин В.Н., Шувалов Г.Н., Минин И.В., Минин О.В. // Опт. и спектр. 2020. Т. 128. В. 6. C. $783-789$.

[19] Qiu Y., Cai G., Su M., Chen T., Zheng X., Xu Y., Ni Y., Zhao A., Xu L.X., Cai S., Jia W. // J. Proteome Res. 2009. V. 8. N 10. P. 4844-4850. 
[20] Coussens L.M., Werb Z. // Nature. 2002. V. 420. P. 860-867.

[21] Новищкий В.В., Рязанцева Н.В., Степовая Е.А. Физиология и патофизиология эритроцита. Томск: Наука, 2004. $202 \mathrm{c}$.

[22] Мейерхардт Джс., Сандерз М. Рак толстой кишки / Под ред. Скарина А.Т. М.: ООО Рид Элсивер, 2009. 186 с.

[23] Ballinger A.B., Anggiansah C. // B.M.J. 2007. V. 335. P. 715718.

[24] Rozen P., Young G.P., Levin B., Spann S.J. Colorectal Cancer in Clinical Practice: Prevention, Early Detection and Management. London: Taylor and Francis, 2006. 534 p.

[25] Козинеи Г.И., Макарова В.А. Исследование системы крови в клинической практике. М.: Изд-во Триада-Х, 1997. $480 \mathrm{c}$.

[26] Markowitz S.D., Bertagnolli M.M. // N. Engl. J. Med. 2009. V. 361. P. 2449-2460. 